\title{
MASJID SEMARANG DALAM PERTARUNGAN RUANG SOSIAL-BUDAYA
}

\author{
Fatah Sukur \\ IAIN Walisongo, Semarang
}

\begin{abstract}
Abstrak: idealnya, masjid tidak hanya digunakan untuk aktivitas shalat saja, melainkan juga berbagai kegiatan keislaman lainnya. Masjid Nurul Islam, Perumaham Mangkang Kulon, Semarang menjadi contoh dari masjid yang digunakan oleh masyarakat sekitar untuk berbagai aktivitas keagamaan Islam. Masjid ini membentuk perwujudan dan kesinambungan historis perkembangan agama Islam di Tanah Air. Filosofi ini diterjemahkan dalam Candrasengkala yang dirangkai dalam kalimat "Sucining Guna Gapuraning Gusti" yang berarti Tahun Jawa 1943 atau Tahun Masehi 2001 adalah tahun dimulainya realisasi dari gagasan pembangunan Masjid Agung Jawa Tengah. Candrasengkala ini terwujud menjadi ekspresi jatidiri Masjid Agung yang megah dan indah, perpaduan unsur budaya universal maupun lokal dalam kebudayaan Islam.
\end{abstract}

Kata Kunci: Masjid, Semarang, Ruang Sosial-Budaya, Ibadah, dan Masyarakat.

\section{A. Pendahuluan}

Masjid kerap hanya digunakan untuk shalat lima waktu. Di luar waktuwaktu itu, sering tampak sepi dan lengang dari kegiatan keislaman. Jamaah yang mengunjunginya pun tidak terlalu banyak, kecuali pada saat-saat tertentu, terutama saat jum'atan dan pelaksanaan shalat Ied yang jatuh setahun dua kali. Kodisi ini menjadi sangat ironis apabila dibandingkan dengan kondisi sejarah dan budaya Islam di Nusantara, yakni masjid memiliki peranan yang sangat penting dalam aktivitas sosial. Sesuai dengan Misi Dewan Masjid Indonesia (DMI), paling tidak ada tiga fungsi masjid. Pertama, masjid sebagai ibadah (mahdlah) juga merupakan tempat beribadah secara luas (ghairu mahdlah) selama dilakukan dalam batas-batas syariah. Kedua, masjid sebagai wadah pengembangan masyarakat melalui berbagai sarana dan prasarana yang dimiliki masjid yang bersangkutan. Ketiga, masjid sebagai pusat komunikasi dan persatuan umat. 
Dari hasil kajian Puslitbang Kehidupan Beragama, digambarkan antara lain bahwa pada tingkat praktis hanya beberapa masjid yang mampu memenuhi ketiga fungsi masjid di atas. Umumnya, jumlah masjid di beberapa wilayah di Indonesia yang ribuan itu belum diiringi dengan kualitas manajemen pengelolaannya. Manajemen yang dipakai relatif belum bisa merespon tuntutan masyarakat yang semakin peduli terhadap pemberdayaan masyarakat masjid sebagai basis pemberdayaan umat.

Pemberdayaan umat ini juga beranjak dari kondisi masyarakat kota yang mayoritas beragama Islam. Di kalangan mayoritas muslim tersebut di hadapkan pada beragam persoalan. Sebut saja masalah kemiskinan, putus sekolah, kesehatan dan kebodohan. Persoalan ini justru banyak ditemukan di daerahdaerah kantung Islam. Padahal, banyak juga umat muslim memiliki kemampuan ekonomi yang memadai, namun terkadang tidak tahu kemana sumbangan mau disalurkan. Model masjid yang berupaya memanfaatkan melalui pengelolaan potensi umat, salah sat unya Masjid Nurul Islam, Perumaham Mangkang Kulon, Semarang. Masjid ini memang bukan kategori masjid tua atau masjid wali. Akan tetapi, keberadaannya di tengah-tengah perumahan, maka masjid ini memiliki fungsi strategis dalam pemberdayaan umat yang notabene menaungi dari seluruh umat Islam yang ada di wilayah tersebut. Masjid ini tetap mempertahankan budaya-budaya Islam yang ada sehingga eksistensinya bertahan hingga sekarang.

Tulisan ini berusaha untuk mengkaji tentang peranan Masjid Nurul Islam, Perumaham Mangkang Kulon, Semarang. Masjid sebagai ruang sosial-budaya dipahami oleh masyarakat dengan berbagai macam sudut pandang. Oleh karena itu, wacana tentang lokalitas dan usaha pemberdayaan umat menjadi sangat penting untuk digali dalam tulisan ini.

\section{B. Peranan Masjid}

Pengembangan masjid dengan melibatkan langsung umat sekitarnya akan lebih terasa manfaatnya. Ide-ide dari masyarakat sekitar masjid diharapkan mampu dalam pengembangan manajemen masjid.Untuk itu sangatlah tepat untuk dilakukan sosialisasi dan langkah nyata untuk pemberdayaan umat, mulai dengan memberikan motivasi, pendidikan pelatihan dan kerjasama kemitraan (Ayub dkk., 1996: 13).

Rasulullah SAW telah memberikan contoh ketika membangun masjid, baik untuk yang pertama di Quba' maupun di Madinah. Masjid yang dibangun Nabi tidak hanya dimaksudkan untuk sarana beribadah mahdhoh kepada Allah SWT semata, melainkan juga untuk membentuk aktivitas sosial. Masjid kala itu, 
digunakan untuk bermusyawarah juga mengaji. Selain itu, beberapa aktivitas sosial masyarakat berada di dekat masjid karena dianggap sebagai pusat spiritualitas.

Masjid juga digunakan sebagai sarana mencerdaskan umat, sebagai sarana berkomunikasi antara umat dan sekaligus sebagai pusat kegiatan umat secara positif dan produktif. Kondisi ini kemudian juga dilestarikan oleh para penggantinya (Khulafa' al-Rasyidun). Namun, seiring dengan berlalunya zaman, masjid mulai ditinggalkan umatnya, kecuali hanya untuk beribadah semata. Fungsi-fungsi yang lain sudah dipisahkan dengan masjid. Masjid hanya dijadikan tempat untuk melaksanakan shalat, pengajian dan kegiatan-kegiatan ke-agama-an saja. Kondisi inilah yang dapat kita lihat saat ini, termsuk di Indonesia.

Kondisi seperti itu, barang kali termasuk masjid-masjid besar tingkat kabupaten/kota, walaupun harus diakui sudah ada upaya-upaya yang dilakukan oleh sebagaian umat Islam untuk menjadikan masjid tidak saja sebagai sarana beribadah semata, tetapi juga sebagai sarana kegiatan umat Islam yang lain, seperti kegiatan sosial, pendidikan, dan lainnya, namun uapaya-upaya tersebut belum banyak dan maksimal.

Dalam rangka untuk melestarikan dan mengembangkan masjid, kiranya diperlukan pemikiran dan gagasan inovatif dan sekaligus kemauan semua pihak, terutama para pengelolanya. Mengelola masjid pada zaman sekarang ini memerlukan ilmu dan ketrampilan manajemen. Pengurus masjid (takmir) harus mampu menyesuaikan diri dengan perubahan zaman.

Di bawah sistem pengelolaan masjid yang tradisional, umat Islam akan sangat sulit berkembang. Bukannya tambah maju, mereka malahan akan tercecer dan makin jauh tertinggal oleh perputaran zaman. Masjid niscaya akan berada pada posisi yang stagnan, yang pada akhirnya bisa ditinggal oleh jamaahnya.

\section{Masjid Semarang}

Semarang, ibukota Provinsi Jawa Tengah, dikenal sebagai salah satu pusat penyebaran agama Islam di Pulau Jawa. Kota ini didirikan pada akhir abad ke-15 oleh Sultan Pandanaran, seorang maulana dari Arab yang diut us Kesultanan Demak oleh Sunan Kalijaga untuk membuka hutan dan menyebarkan agama Islam. Di daerah ini pula, Sultan Pandanaran mendirikan masjid untuk umat Islam. Masjid didirikan di pusat kota sehingga ketika waktu shalat tiba, umat Islam dapat dengan segera beribadah. 
Kini setelah enam abad berlalu, kota Semarang memperlihatkan jati dirinya sebagai tempat berkembangnya agama Islam. Salah satu bukti adalah berdirinya bangunan Masjid Agung Jawa Tengah, yang terletak di jalan Gajah Raya, kelurahan Sambirejo, Gayamsari. Bangunan di atas tanah seluas 10 hektar hasil wakaf dari Masjid Kauman ini menjadi bangunan termegah dan terbesar di Jawa Tengah. Masjid yang dibangun tahun 2002 dan diresmikan penggunaannya tahun 2006 ini menelan dana sebesar Rp 200 miliar. Gaya arsitektur Masjid Agung Jawa Tengah merupakan perpaduan antara budaya Jawa, Timur Tengah, dan Yunani. Masjid berdiri megah dengan 25 pilar koloseum dan kaligrafi yang Indah.

Bangunan ini begitu mempesona dengan keberadaan arsitektur Jawa yang diaplikasikan dalam bentuk limasan, seperti yg terdapat pada masjid Kudus, serta arsitektur Islam yang terkenal dengan empat minaret seperti pada masjid Nabawi di Madinah. Masjid ini mampu menampung 17.000 ribu jamaah yang terbagi 7 ribu jamaah di dalam masjid dan 10 ribu jamaah di plaza yang dilengkapi 6 payung raksasa hidrolik. Di dalam masjid juga terdapat bedug raksasa yang dinamakan bedug ijo dengan panjang $310 \mathrm{~cm}$ dan diameter 220 $\mathrm{cm}$.

\section{Sejarah Berdirinya}

Ibarat dua sisi mata uang, membicarakan Masjid Agung Jawa Tengah tak bisa lepas dari Masjid Agung Kauman, Semarang. Hal ini karena Masjid Agung Jawa Tengah ada karena Masjid Agung Kauman, Semarang. Masjid Agung Kauman di Jalan Alun-aloun Barat Kauman, Semarang mempunyai tanah Banda Masjid seluas 119,1270 Ha yang dikelola oleh Badan Kesejahteraan Masjid (BKM), organisasi bentukan Bidang Urusan Agama Islam (Urais) Departemen Agama.

Dengan alasan tanah seluas 119,1270 itu tidak produktif oleh BKM ditukar guling (ruislag) dengan tanah seluas 250 hektare di Kabupaten Demak lewat PT. Sambirejo. Dari PT. Sambirejo kemudian berpindah kepada PT. Tens Indo Tjipto Siswojo. Singkat cerita, proses ruilslag itu tidak berjalan mulus, tanah di Demak itu ternyata ada yang sudah jadi laut, sungai, kuburan dan lain-lain. Walhasil Tanah Banda Masjid Agung Kauman Semarang hilang, raib akibat dikelola oleh manusia-manusia jahat dan tidak amanah.

Lewat jalur hukum dari Pengadilan Negeri Semarang hingga Kasasi di Mahkamah Agung, Masjid Agung Kauman (BKM) selalu kalah.Akhirnya sepakat dibentuk Tim Terpadu yang dimotori oleh Badan Koordinasi Stabilitas Nasional Daerah (Bakorstanasda) Jawa Tengah / Kodam IV Diponegoro.Pada 
waktu itu Pangdam IV / Diponegoro dijabat Mayjen TNI Mardiyanto (yang akhirnya menjadi Gubernur Provinsi Jawa Tengah dan Menteri Dalam Negeri).Tim ini awalnya dipimpin Kolonel Bambang Soediarto, kemudian dilanjutkan oleh Kolonel Art Slamet Prayitno, Kepala Badan Kesbanglinmas Provinsi Jawa Tengah pada waktu itu.

Pada Jumat Legi 17 Desember 1999, usai shalat Jumat di Masjid Agung Kauman, ribuan umat Islam bermaksud memberi tekanan kepada Tjipto Siswojo agar menyerahkan tanah-tanah itu kembali kepada masjid. Mereka melakukan perjalanan panjang dari Masjid Agung Kauman menuju rumah Tjipto Siswojo di Jalan Branjangan 22-23, kawasan Kota Lama Semarang.

Akhirnya, melalui proses panjang yang berbelit-belit dan melelahkan, Tjipto Siswojo mau menyerahkan sertifikat tanah-tanah itu kepada masjid. Meskipun ketika dia menyerahkan, Tjipto mengaku bukan karena tekanan dari siapa pun, tetapi masyarakat sudah terlanjur meyakini Tjipto menyerahkan harta bendanya karena pada Jumat legi 17 Desember itu. Kemudian dibentuk Tim Terpadu dengan Ketua Kolonel Bambang Soediarto (dari Kodam IV/ Diponegoro) dan Sekretaris Slamet Prayitno (Kepala Badan Kesbanglinmas Jawa Tengah).

Pada periode awal yang paling intens mengupayakan proses pengembalian tanah banda masjid yang hilang ini antara lain; KH MA Sahal Mahfudh (waktu itu Ketua Umum MUI Jawa Tengah), Drs. H Ali Mufiz MPA (waktu itu Ketua MUI Jawa Tengah/Dosen Fisip Undip Semarang. Selanjutnya menjadi Wakil Gubernur Jawa Tengah berpasangan dengan H Mardiyanto. Ali Mufiz pada 28 September 2007 dilantik menjadi Gubernur Jawa Tengah karena H Mardiyanto menjadi Menteri Dalam Negeri), Dr. H Noor Achmad, MA (anggota DPRD Jawa Tengah/waktu itu, Ketua Badan Koordinasi Pemuda dan Remaja Masjid Indonesia BKPRMI Jateng), dan Drs. HM Chabib Thoha, MA. (Sekretaris Umum MUI Jawa Tengah akhirnya menjadi Kepala Kanwil Departemen Agama Jawa Tengah). Mereka hampir setiap hari berkumpul di Kantor MUI Jawa Tengah (sebelah utara Masjid Raya Baiturrahman) Simpanglima Semarang.

Gerakan umat pun terus berlanjut bak gayung bersambut. Masyarakat Kauman bersama seluruh elemennya terus berjuang agar tanah-tanah bandha masjid itu kembali. KH Turmudzi Taslim AlHafidz (almarhum), KH Hanief Ismail Lc, H Hasan Thoha Putra MBA, Ir H Hammad Maksum, H Muhaimin S.Sos dan lain-lain adalah sebagian nama-nama yang menyemangati gerakan tersebut. Sementara lewat gerakan spiritual Drs KH Dzikron Abdullah, KH Amdjat Al-Hafidz, KH Kharis Shodaqoh, KH Muhaimin, KH Masruri Mughni memberikan dukungan lewat jalur lain. 


\section{E. Budaya dalam Masjid Semarang}

Masjid Agung Jawa Tengah memiliki banyak keistimewaan. Semua detil yang ada di Masjid Agung Jawa Tengah (MAJT) istimewa dibanding bangunan masjid yang ada di Indonesia, bahkan dunia sekalipun. Luas areal tanahnya saja spektakuler: 10 Hektare. Luas Bangunan Induk atau Bangunan Utama untuk Shalat: $7.669 \mathrm{~m}^{2}$. Bangunan Utama terdiri dua lantai, lantai satu untuk jamaah pria, lantai dua untuk jamaah perempuan.Kapasitas ruang utama diperkirakan bisa menampung 6.000 orang jamaah. Di dalam bangunan induk dilengkapi dengan empat buah Minaret masing-masing tingginya 62 meter. Salah satu Minaret dilengkapi dengan lift yaitu Minaret bagian Depan (Timur) Kanan. Kubah utama berbentuk setengah lingkaran dari cor beton dengan garis tengah 20 meter.

Gaya arsitektur masjid, merupakan perpaduan antara Jawa, Timur Tengah (Arab Saudi) dan Yunani.Gaya Timur Tengah terlihat dari Kubah dan empat minaretnya. Gaya Jawa terlihat dari bentuk tajugan di atap di bawah kubah utama. Sedang gaya Yunani terlihat pada 25 pilar-pilar Kolasium dipandu dengan kaligrafi Arab yang sangat indah.

Filosofi perancangan Masjid Agung Jawa Tengah merupakan perwujudan dan kesinambungan historis perkembangan agama Islam di Tanah Air. Filosofi ini diterjemahkan dalam Candrasengkala yang dirangkai dalam kalimat "Sucining Guna Gapuraning Gusti" yang berarti Tahun Jawa 1943 at au Tahun Masehi 2001 adalah tahun dimulainya realisasi dari gagasan pembangunan Masjid Agung Jawa Tengah. Candrasengkala ini terwujud menjadi ekspresi jati diri Masjid Agung yang megah dan indah, perpaduan unsur budaya universal maupun lokal dalam kebudayaan Islam.

Di masjid ini juga terdapat plasa. Pada plasa ini terdapat Banner yang dinamakan Gerbang Al-Qanathir yang artinya "Megah dan Bernilai".Tiang pada Gerbang Al-Qanathir ini berjumlah 25 buah merupakan simbolisasi dari 25 rosul Allah sebagai pembimbing umat.Pada Banner Gerbang ini bertuliskan kaligrafi kalimat Syahadat Tauhid "Asyhadu Alla Illa Ha Illallah' dan Syahadat Rasul “Asyhadu anna Muhammadar Rosulullah”. Sedang pada bidang datar tertulis huruf pegon berbunyi "Sucining Guna Gapuraning Gusti".

Plasa masjid seluas 7500 meter persegi ini merupakan perluasan ruang shalat yang dapat menampung kurang lebih 10.000 jamaah. Dilengkapi dengan 6 payung raksasa yang bisa membuka dan menutup secara otomatis seperti yang ada di masjid Nabawi di Madinah.Konon di dunia hanya ada dua masjid yang dilengkapi dengan payung elektrik semacam ini.Tinggi tiang payung elektrik 
masing-masing 20 meter sedangkan bentangan (jari-jari) masing-masing 14 meter.

Di dalam ruang utama Masjid Agung Jawa Tengah terdapat al-Qur'an Raksasa (Mushaf Al-Akbar) karya Santri Pondok Pesantren al-Asy'ariyyah Kalibeber, Mojotengah, Wonosobo (Pendiri: KH. Muntaha AlHafidz). Disebut Mushaf Al-Akbar karena ukuran yang besar yaitu $145 \mathrm{~cm}$ x $95 \mathrm{~cm}$. Al-Qur'an tersebut kini diletakkan di Museum Sejarah Islam di lantai dua Menara Al-Husna Kompleks Masjid Agung Jawa Tengah.

Di dalam Masjid bagian Timur Utara juga terdapat Bedug Raksasa Karya KH. Ahmad Shobri, Tinggarjaya, Jatilawang, Purwokerto Banyumas. Bedug bernama "Bedug Ijo" Mangunsari dibuat pada 20 Sya'ban 1424 H. Panjangnya $310 \mathrm{~cm}$. Garis Tengah Depan/Belakang $186 \mathrm{~cm}$. Garis tengah bagian Tengah $220 \mathrm{~cm}$ Keliling depan/belakang $588 \mathrm{~cm}$. Keliling Tengah $683 \mathrm{~cm}$. Jumlah paku 156 buah. Yang istimewa, kata Kiai Shobri, Dukuh tempat dibuatnya bedug namanya Mangunsari dari Bahasa Arab Maun Syaar artinya pertolongan dari kejelekan.Terbuat dari Kayu Waru pilihan dan kata orang pohon yang angker.Pembuatnya harus selalu dalam keadaan wudlu dan puasa.Kiai Shobri juga membuat Kentongan Ijo yang diletakkan bersebelahan dengan Bedug Ijo.

Di bawah bangunan utama terdapat tempat wudlu pria/wanita.Terdapat 93 kran wudlu pria dan 56 kran wudlu wanita.Di tempat wudlu sayap kanan terdapat 50 buah kran wudlu sedang di tempat wudlu sayap kiri terdapat 14 buah.Di bawah bangunan utama juga terdapat Ruang Perkantoran Badan Pengelola, Gedung Serbaguna dan Ruang VIP yang akses langsung ke ruang Imam.

Bangunan sayap kanan adalah Convention Hall (auditorium) yang mampu menampung 2.000 orang. Sedang bangunan sayap kiri adalah Perpustakaan yang nantinya didesain menjadi perpustakaan modern "Digital Library"dan Office Space ruang perkantoran yang disewakan, Di bawah Plasa Masjid Agung Jawa Tengah adalah tempat parkir yang mampu menampung 680 mobil dan 670 sepeda motor.

Masjid Agung Jawa Tengah juga dilengkapi dengan Wisma Penginapan Graha Agung dengan kapasitas 23 kamar berbagai kelas. Para peziarah atau pengunjung yang ingin bermalam bisa memanfaatkan fasilitas tersebut dengan harga yang sangat murah. Wisma penginapan ini terletak di bagian Timur utara Masjid.

Daya tarik lainnya yaitu Menara Al-Husna (Al-Husna Tower). Tingginya 99 meter ittibak pada angka Al-Asmaul Husna. Bagian dasar menara terdapat 
Studio Radio DAIS (Dakwah Islam). Lantai 2 dan 3 untuk Museum Kebudayaan Islam. Di lantai 18 terdapat kafe muslim yang bisa berputar 360 derajat. Sambil menikmati hidangan dan lagu-lagu Islami, di kafe ini bisa menikmati indahnya kota Semarang. Lantai 19 untuk menara pandang. Dilengkapi dengan 5 teropong yang bisa melihat pemandangan Kota Semarang. Pada awal Ramadhan 1427 H, untuk kali pertama dipakai Rukyatul Hilal dari Tim Rukyah Jawa Tengah menggunakan teropong canggih dari BOSCA.

Yang menginginkan wisata kuliner, di bagian selatan MAJT (Blok C) dan di bagian depan/timur masjid (Blok A dan B) terdapat PUJASERA yang menyediakan aneka hidangan.

Berbagai aktivitas spiritual di Masjid Agung Jawa Tengah yang bisa diikuti umat Islam yaitu Semaan al-Qur'an tiap Jumat pukul 11.00-11.45. Pengajian Ahad Pagi tiap hari Minggu pukul 07.00-08.00. Pengajian Ibu-ibu (PIMA-JT) tiap Jumat Wage pukul 13.00-15.00. Pengajian Remaja (Risma-JT) tiap Malam Minggu Wage pukul 20.00-22.00 bersama Habib Umar Muthohar SH. Mujahadah ASMAUL HUSNA Tiap Kamis malam pukul 23.00-00.30 bersama Drs KH Amdjad Al-Hafidz.KAJIAN FIQIH tiap Minggu pukul 18.00-19.00. Kajian Tafsir al-Qur'an tiap Rabu pukul 19.00-19.00. Kajian Hadist tiap Kamis pukul 18.00-19.00. Seni Baca al-Qur'an (Tilawatil Qur'an) tiap Kamis 19.3020.30. Kajian Tasawuf tiap Jumat pukul 18.00-19.00.

Untuk pelayanan kesehatan kepada jamaah, Masjid Agung Jawa Tengah mempunyai Poliklinik dua poly yaitu Poly Umum dan Poly Gigi.Masjid Agung Jawa Tengah mempunyai empat imam masing-masing Hafidz (hafal) al-Qur'an 30 juz.Mereka tidak hanya hafal tetapi ketika melantunkan ayat al-Qur'an saat Shalat Maghrib, Isya dan Shubuh juga tarawih harus dengan lagu seperti di Masjidil Haram. Mereka adalah KH. Ulil Abshor Al-Hafidz dari Jepara, KH. Zaenuri Ahmad Al-Hafidz dari Salatiga, KH.Ahmad Thoha dari Pekalongan dan KH. Muhaimin Al-Hafidz. Sedang Muadzin yaitu Mohammad Rokhani, Muhammadun Zen dan Muhammad Yusuf.

Masjid ini menjadi daya tarik masyarakat, tidak hanya yang ingin beribadah shalat.Tetapi banyak yang sekaligus memanfaatkan untuk berwisata.Lihatlah pada akhir pekan Sabtu dan Minggu. Di Masjid ini penuh sesak dengan para pengunjung.Untuk sekadar mencari makanan dan minuman di sekitar masjid terdapat puluhan bahkan ratusan pedagang berbagai aneka menu makanan yang lezat.Mereka tertata apik dalam bangunan-bangunan kecil yang dikelola oleh Lembaga Pengembangan Usaha (LPU) Masjid Agung Jawa Tengah. 
Para peziarah biasanya datang tidak mengenal waktu, bisa siang hari, malam hari bahkan tengah malam dan dinihari. Biasanya mereka datang menggunakan bus bisa mencapai puluhan bus. Tamu-tamu pejabat juga menyempatkan datang seperti rombongan DPR RI, Dewan Perwakilan Daerah (DPD) RI, Lemhanas, peserta-peserta kursus, penataran, instansi dan lainlain.Luar biasa memang.

Beberapa tamu dari luar negeri yang sudah bersilaturahim dan mengunjungi Masjid Agung Jawa Tengah yaitu Yunani, Arab Saudi, Qatar, Uni Emirat Arab, Kuwait, Oman, Amerika Serikat, Jepang, China, wartawan Zimbabwe Afrika, para ulama dari Hadramaut Yaman, Australia, RRC, Mesir, Iran, Irak, Suriname dan lain-lain.

\section{F. Ruang Sosial-Budaya Masjid Semarang}

Masjid Agung Jawa Tengah telah diberdayakan untuk berbagai kegiatan ibadah, kaum muslimin melakukan i'tikaf, membersihkan diri, menggembleng batinguna membina kesadaran dan mendapatkan pengalaman batin/keagamaan sehingga selalu terpelihara keseimbangan jiwa dan raga serta keutuhan kepribadian.

Dakwah yang dikembangkan dalam Masjid Agung Jawa Tengah adalah menitikberatkan pada peningkatkan kualitas pemahaman dan amal keagamaan pribadi muslim, melalui juru dakwah dan penyuluh agama yang dibina oleh pengurus masjid. Latar belakang jamaah masjid ini dari berbagai unsur aliran keagamaan, demikian juga dari berbagai suku dan tingkat pendidikan. Maka pengurus melakukan berbagai kegiatan keagamaan yang berfungsi sebagai dakwah, misalnya kajian islam bulanan dengan menampilkan tokoh organisasi Islam dari majelis ulama indonesia, peringatan hari-hari besar islam, serta menampilkan khotib-khotib berwawasan luas keagamaannya.

Selain dari kajian Islam bulanan, juga ada pengajian khusus kaum ibu lansia, dewasa dan remaja. Materi keagamaan disampaikan ustadz dan ustadzah cukup menarik sehingga jumlah pesertanya lumayan banyak. Pembinaan pengajian di kalangan kaum dhuafa' dan anak yatim dilakukan sebulan sekali, sekaligus penyantunan terhadap mereka.

Pendidikan di masjid fokus utamanya adalah menanamkan pendidikan agama kepada anak-anak sejak dini sehingga mereka diharapkan kelak bisa tumbuh menjadi sosok pribadi muslim yang benar-benar memahami, menghayati, dan dapat mengamalkan ajaran agama dengan baik. Hal itu ditunjukan melalui kemampuan dalam membaca ayat-ayat al-Qur'an dengan baik, melaksanakan ibadah shalat dengan baik, terdorong untuk giat melakukan 
ibadah ritual, menjiwai ajaran dan nilai-nilai agama, serta terjaga akhlaknya, termasuk budi pekerti yang luhur di dalamnya. Kelompok pendidikan ini, termasuk anak didik dari anak yatim dan dzuafa yang mendapatkan santunan dari masjid nurul Islam.

\section{G. SimpUlan}

Masjid Nurul Islam, Perumaham Mangkang Kulon, Semarang telah mengalami pergulatan yang panjang. Masjid ini juga dikenal dengan Masjid Agung Jawa Tengah (MAJT), yang memiliki filosofi Candrasengkala yang dirangkai dalam kalimat "Sucining Guna Gapuraning Gusti" yang berarti bahwa masjid ini akan mengarahkan pada Umat Islam untuk membersihkan diri dari hal-hal yang buruk. Oleh karena itu, di masjid ini dibentuklah kajian-kajian Islam sebagai budaya dan aktivitas kemasyarakatan. Kajian-kajian Islam diarahkan untuk membentuk pemahaman masyarakat dan usaha untuk menjadikan masjid sebagai bagian dari kehidupan. Di masjid ini juga ditanamkan nilai-nilai luhur lokal yang Islami sebagai jati diri orang Jawa agar masyarakat tidak terbawa oleh arus globalisasi.

\section{Daftar Pustaka}

al-Faruqi, Ismail Raji. 1998. Atlas Budaya islam: Menjelajah Khasanah Peradaban Gemilang (the Culture Atlas of Islam) diterj. oleh Ilyas Hasan. Bandung: Mizan.

Moh. E, Ayub, dkk 1996. Manajemen Masjid, Petunjuk Praktis bagi Para Pengurus. Jakarta: Gema Insani.

Munir, M dan Wahyu Ilahi. 2006. Manajemen Dakwah. Jakarta: Prenada Media. Shihab, M. Quraish. 1996. Wawasan al-Qur'an: Tafsir Maudhu'iatas Berbagai Persoalan Umat. Bandung: Mizan.

Supardi dan Teuku Amirudin. 2001. Manajemen Masjid dalam Pembangunan Masyarakat, Optimalisasi peran dan Fungsi Masjid. Yogyakarta: UII Press.

Yani, Ahmad Dkk. 2002. Panduan Mengelola Masjid sebagai Pusat Kegiatan Umat. Bandung: Pustaka Intermasa. 